\title{
Reproductive System Findings Reason Not Done
}

National Cancer Institute

\section{Source}

National Cancer Institute. Reproductive System Findings Reason Not Done. NCI

Thesaurus. Code C117650.

The rationale why a reproductive system finding was not obtained. 